\title{
INTERNAL JUGULAR VENOUS CANNULATION- COMPARISON OF ANTERIOR AND POSTERIOR APPROACH
}

\author{
Manjula B. P1, Deepthi H. V2
}

1 Professor, Department of Anaesthesiology and Critical Care, JSS Medical College, Mysore.

2 Postgraduate Student, Department of Anaesthesiology and Critical Care, JSS Medical College, Mysore.

\section{BACKGROUND}

ABSTRACT

Central venous catheterisation is a vital intervention in critically ill patients. The proper route of insertion is essential for its success.

Objective of this study is to compare procedural parameters and complications associated with anterior and posterior approaches of internal jugular venous cannulation.

\section{MATERIALS AND METHODS}

Our study was conducted as prospective randomised clinical trial in 100 patients posted for elective, emergency surgeries and critically ill patients in intensive care unit. Patients were randomly allocated into two groups of 50 patients each. Demographic data, number of attempts, procedural parameters and incidence of complications were compared in both groups.

\section{RESULTS}

Time for identifying the vein, number of attempts, duration for cannulation and incidence of complications like carotid puncture and haematoma were less in posterior approach when compared to anterior approach.

\section{CONCLUSION}

Posterior approach in internal jugular vein cannulation is safer and it has a better success rate as compared to anterior approach.

\section{KEYWORDS}

Internal Jugular Venous Cannulation, Anterior Approach, Posterior Approach.

HOW TO CITE THIS ARTICLE: Manjula BP, Deepthi HV. Internal jugular venous cannulation- comparison of anterior and posterior approach. J. Evolution Med. Dent. Sci. 2017;6(39):3143-3146, DOI: 10.14260/Jemds/2017/678

\section{BACKGROUND \\ Percutaneous cervical central venous cannulation is now} common during perioperative care in major surgical procedures, critically ill patients in intensive care units for long term hyperalimentation and for rapid restoration of blood volume in cases of acute blood loss. ${ }^{1}$ The proper choice of insertion site is essential for success of cannulation. Placement of central venous catheters via the right internal jugular vein has become one of the most popular routes. ${ }^{2}$

Advantages of right internal jugular vein cannulation relate to the fact that it has got good external landmarks, its consistent and predictable anatomic location, its valve-less course to the superior vena cava and right atrium. ${ }^{3}$

There are numerous approaches for cannulating the internal jugular vein. The anterior approach is being practised widely since the identification of landmarks and palpation of carotid artery permits to learn the procedure easily. The major complications of this approach are carotid puncture and haematoma. The posterior approach moves the point of entry higher up in the neck thus increasing the length

Financial or Other, Competing Interest: None.

Submission 28-02-2017, Peer Review 03-05-2017,

Acceptance 10-05-2017, Published 15-05-2017.

Corresponding Author:

Dr. Deepthi H. V,

H. No. 269 (F-13), Uttaradi Mutt, $4^{\text {th }}$ Cross,

Agrahara, Fort Mohalla,

Near JSS Hospital,

Mysore-570004.

E-mail:dr.deepthihv@gmail.com

DOI: $10.14260 /$ jemds $/ 2017 / 678$ of vein for cannulation and also avoiding the dangers of pneumothorax and haemothorax. ${ }^{4}$ The external jugular vein, which is a landmark for posterior approach could be easily identified by Trendelenburg position. ${ }^{3}$

Hence, we have undertaken this study in hundred patients of ASA Physical Status Class I to IV undergoing elective and emergency surgeries and critically ill patients to compare the procedural parameters and complications associated with each approach.

\section{Literature Survey}

Studies were conducted by Chudari L S et al $^{3}$ to compare the anterior and posterior approaches of internal jugular venous cannulation, Chandralekha $\mathrm{M} \mathrm{V}$ et $\mathrm{al}^{5}$ for comparing palpation method and non-palpation method of internal jugular vein cannulation and Lamkinsi $\mathrm{T}$ et $\mathrm{al}^{6}$ for evaluating best approach to cannulate internal jugular vein. They have concluded that posterior approach is safer and more efficient than anterior approach.

\section{MATERIALS AND METHODS}

The study was undertaken in the Department of Anaesthesiology, Critical care and Pain medicine, JSS Medical College, Mysore during the period from November 2014 to April 2016 after obtaining permission from the Institutional Ethical committee. A pilot study with a sample size of 5 cases in each group was done before the start of the study to decide on sample size. From the results obtained in the pilot study, a target population of 50 subjects in each group was decided. The study was conducted as a prospective randomised study. A written informed consent was obtained from the patients 
on the morning of surgery and from the patients' relatives for critically ill patients.

Patients of either sex with age $\geq 18$ years of age, weight between 40-80 kg Patients of American Society of Anesthesiologists (ASA) Physical Status I to IV undergoing elective and emergency surgeries and critically ill patients in intensive care unit (ICU) were included in the study.

Left internal jugular vein cannulation, patients with localised skin infection in the neck, history of neck surgery, altered neck anatomy, coagulation abnormality and pregnancy cases were excluded from the study.

\section{Patients were randomly classified using computer generated numbers into two groups of 50 each}

- Group A - Patients undergoing right IJV cannulation by anterior approach.

- Group P - Patients undergoing right IJV cannulation by posterior approach.

All routine investigations like complete haemogram, random blood sugar, blood urea, serum creatinine, coagulation profile, chest x-ray, ECG and screening for HIV and HBsAg were done.

Peripheral intravenous access was secured. All the necessary monitoring devices like ECG, pulse oximeter and NIBP were connected. All patients were premedicated with

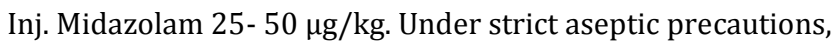
part was painted and draped. The procedure was performed after skin infiltration with $1 \mathrm{~mL}$ of $2 \%$ Lignocaine at the site of insertion. Patients were positioned supine with $20^{\circ}$ head down. The head was turned to the opposite side with not more than $20^{\circ}$ rotation and a support was placed under the shoulders to accentuate the landmarks.

\section{Anterior Approach}

The triangle formed by the two heads of sternocleidomastoid muscle and clavicle was identified. The carotid artery at the medial end of this triangle was palpated. Near the apex of this triangle, a skin wheal was raised with $1 \mathrm{~mL}$ of $2 \%$ Lignocaine. Skin puncture was made at $30^{\circ}$ to the skin with the needle. The direction of the needle was towards the ipsilateral nipple.

\section{Posterior Approach}

The point where the external jugular vein crosses the posterolateral border of sternocleidomastoid muscle is the entry point. A skin wheal was raised at this point with $1 \mathrm{~mL}$ of $2 \%$ lignocaine. The body of the muscle was lifted and the needle was then advanced at an angle of $30^{\circ}$ to the skin directed towards the suprasternal notch.

With constant aspiration, the needle was slowly advanced till two tissue pops were felt at the prevertebral fascia and the vein wall. The position in the vein was confirmed by aspiration of dark blood. The internal jugular vein was cannulated by modified Seldinger's technique. The hub of the cannula was anchored with sutures. A check X-ray was advised after the procedure in all patients for confirming catheter position and to identify complications like pneumothorax and haemothorax.

\section{Parameters Assessed}

Procedural parameters like time taken to identify the vein, number of attempts to identify the vein and duration for cannulation were assessed in both the groups. Complications like carotid puncture, haematoma and catheter kinking were also compared in both the groups.

\section{Statistical Methods Used}

A pilot study was conducted with 5 patients in each group to define the population and decide the criteria for patient selection. In our study, power analysis was computed for 2 factors (anterior and posterior). The mean time for identifying the vein and the standard deviation calculated from the study was used to calculate the sample size. The mean time taken for identifying the vein was $1.69 \pm 0.09 \mathrm{~min}$. \& $1.61 \pm 0.07 \mathrm{~min}$. with anterior approach and posterior approach respectively. The significance level ( $P$ value) was set to $\alpha=0.05$. Power of the study was calculated as 0.84 .

Results of power analysis yielded a target population of 50 patients in each group to achieve a moderate effect size. Randomisation was done by using computer generated numbers. Data was analysed using SPSS version 20 software. Qualitative analysis was done using chi-square test and quantitative analysis by unpaired t-test. P-value of $\leq 0.05$ was considered statistically significant and values $\leq 0.001$ were taken as statistically highly significant.

\section{RESULTS}

Data was collected and statistical analysis was performed as explained in the methodology of the study. Patients in both the groups were comparable by age, gender, height and weight $(\mathrm{P}>0.05)$.

Time taken for identification of vein was lesser with posterior approach $(0.2 \pm 0.12$ minutes $)$ as compared to anterior approach $(1.05 \pm 0.37$ minutes $)$ which was significantly lower with anterior approach (Graph 1).

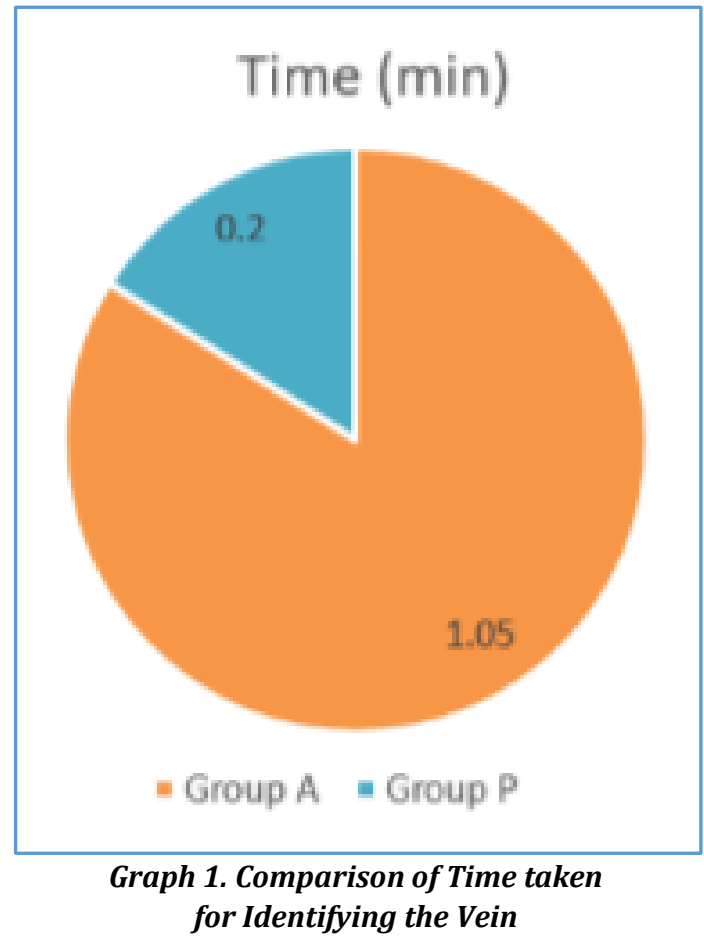

Number of attempts required for cannulation is lesser with posterior approach as compared to anterior approach (Graph 2). In group A, only 10 patients were cannulated in 
the 1st attempt, whereas it was 33 patients in group P. Pvalue was 0.0002 which is statistically highly significant.

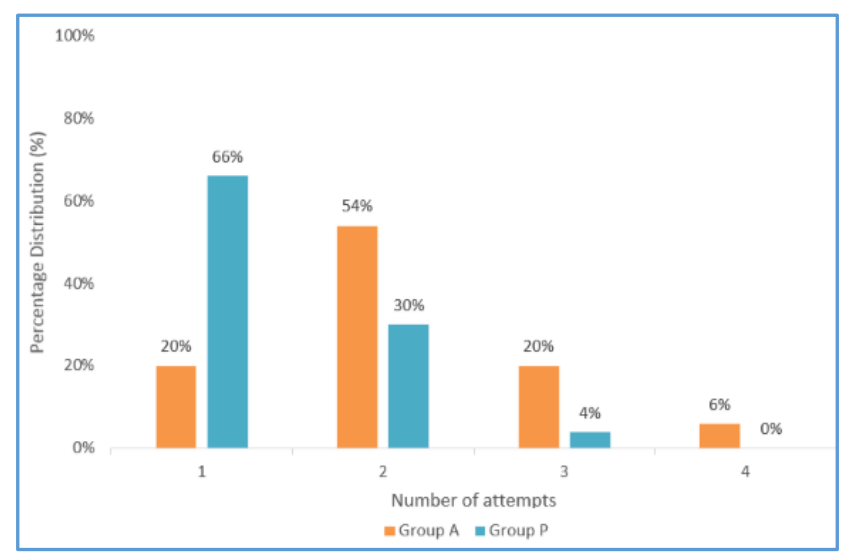

Graph 2. Comparison of Number of Attempts Required in Both Groups

Duration for cannulation with posterior approach was $1.38 \pm 0.18$ minutes whereas it was $3.05 \pm 1.06$ minutes with anterior approach

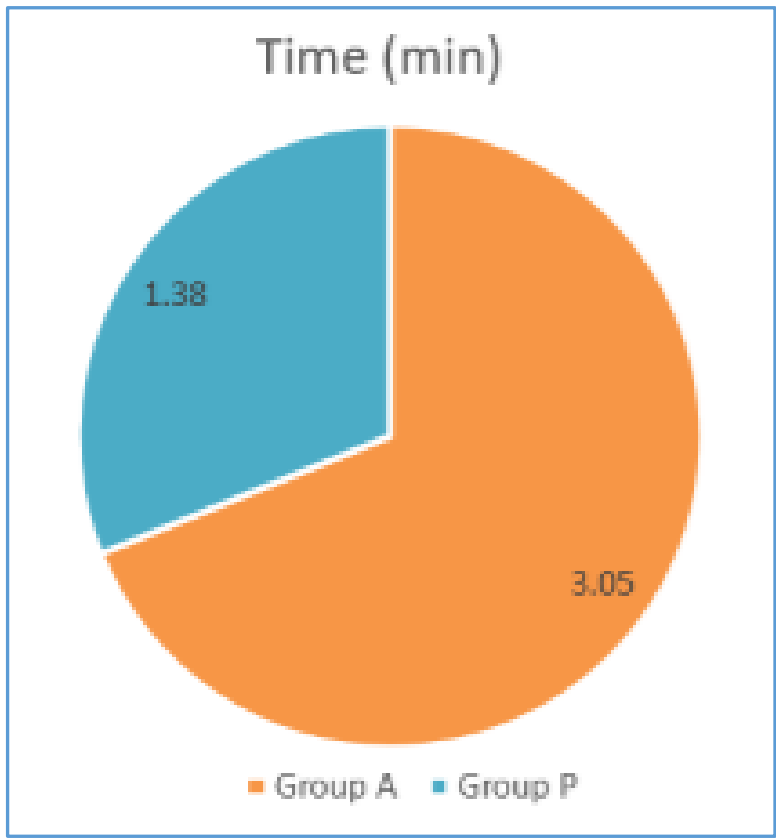

Graph 3. Comparison of Duration for Cannulation in Both the Groups

Complications associated with both the approaches were compared. Carotid puncture was encountered in 11 patients in group A and in only 3 patients in group P. Haematoma was observed in 10 patients in group A, while it was observed in only 2 patients in group P. There was kinking of the catheter in 8 patients in group $\mathrm{A}$ and in just 2 patients in group $\mathrm{P}$. (Table 1).

\begin{tabular}{|c|c|c|}
\hline Complication & $\begin{array}{c}\text { Anterior } \\
\text { Approach }\end{array}$ & $\begin{array}{c}\text { Posterior } \\
\text { Approach }\end{array}$ \\
\hline Carotid Puncture & $11(22 \%)$ & $3(6 \%)$ \\
\hline Haematoma & $10(20 \%)$ & $2(4 \%)$ \\
\hline Catheter Kinking & $8(16 \%)$ & $2(4 \%)$ \\
\hline Pneumothorax & Nil & Nil \\
\hline Table 1. Incidence of Complications in Both the Approaches
\end{tabular}

Pneumothorax and Haemothorax were not seen in any patients in both the groups. Other complications like arrhythmias and thrombophlebitis were lower in posterior approach, but the difference was not statistically significant.

\section{DISCUSSION}

Internal jugular vein can be cannulated by various approaches, but the success depends on anatomical variations and operator experience. Different approaches have been described depending on the level of the neck at which the vein is punctured. A high approach reduces the risk of pneumothorax but increases the risk of arterial puncture and vice versa for lower approaches. ${ }^{7}$ Our study compares the widely practised anterior approach with posterior approach.

The parameters for comparison were selected based on the inferences in various clinical trials and studies. Most of the studies correlate the anatomical variations of internal jugular vein and the relations to carotid artery with the success rate. $3,5,6$ Hence, criteria like number of attempts, time taken for identification of the vein, duration of cannulation, carotid puncture, haematoma, catheter kinking and catheter displacement were considered for comparison.

The number of attempts required for successful cannulation is lesser with posterior approach as compared to anterior approach (Graph 2). This is because the identification of landmarks i.e. the two heads of sternocleidomastoid can be difficult, especially in obese and short necked patients, whereas posterior approach requires identification of only the bulk of sternocleidomastoid muscle. ${ }^{3}$ The other reason could be the anatomical variations of common carotid artery in relation to internal jugular vein and external landmarks may not correlate exactly to the location of the vessels. ${ }^{8}$

The present study correlates well with the study conducted by Chudhari LS et $\mathrm{al}^{3}$ and Mohan Chandralekha V et $\mathrm{al}, 5$ both the studies showing lesser attempts for cannulation with posterior approach.

The time taken for identifying the vein and duration for cannulation were also less with posterior approach (Graph 1, 3), which correlates with the study conducted by Lamkinsi et al. ${ }^{6}$ The reason for less time consumption in the posterior approach is that the cross-sectional area of the vein is greater in the posterior approach than the anterior approach in the Trendelenburg position. A larger crosssectional area in the posterior approach permits earlier identification of the vein and easy threading of the catheter. ${ }^{8}$

The incidence of carotid puncture and haematoma was more with anterior approach (Table 1). Our results were similar to a study conducted by Mohan Chandralekha $V$ et al. ${ }^{5}$ Haematoma can develop rapidly following carotid puncture or slowly following multiple punctures on the vein due to difficult cannulation or threading. ${ }^{9}$ In all cases of carotid punctures, the needle was withdrawn and firm pressure was applied. By anterior approach, compression is difficult against the clavicle and the haematoma formed is larger. ${ }^{3}$ The risk of arterial puncture can be almost completely eliminated by the routine use of ultrasound needle guidance. ${ }^{10}$

Catheter kinking and displacement were also commonly seen with central venous catheterisation. Kinking of the catheter leads to inadequate central venous pressure monitoring. Kinking can be recognised by inability to aspirate 
dark blood from the catheter and absent or distorted CVP waveforms. In our study, there was a higher rate of catheter kinking in the anterior method.

\section{CONCLUSION}

Based on our study, we conclude that posterior approach is easier to cannulate as compared to anterior approach in terms of number of attempts, time taken for identifying the vein and duration for cannulation. The incidence of complications like carotid puncture and haematoma is also significantly lower with posterior approach.

\section{REFERENCES}

[1] Duffy M, Sair M. Cannulation of central veins. Anaesthesia \& Intensive Care Medicine 2007;8(1): 17-20.

[2] Belani K, Buckley J, Gordon J, et al. Percutaneous cervical central venous line placement: a comparison of the internal and external jugular vein routes. Anaesthesia \& Analgesia 1980;59(1):40-4.

[3] Chudhari LS, Karmarkar US, Dixit RT, et al. Comparison of two different approaches for internal jugular vein cannulation in surgical patients. J Postgrad Med 1998;44(3):57-62.

[4] English ICW, Frew RM, Pigott JFG. Percutaneous catheterization of the internal jugular vein. Thorax 1969;24(4):496-7.
[5] MohanChandralekha V, Darlong V, Kashyap L. Internal jugular vein cannulation comparison of central approach (palpation method) and posterior approach (nonpalpation method): A766. European Journal of Anaesthesiology 2005;22(Supplement 34):197-8.

[6] Lamkinsi T, Kettani A, Belkhadir Z, et al. Internal jugular venous catheterization: what is the best approach? Annales Françaises d'Anesthésie et de Réanimation 2012;31(6):512-6.

[7] Key W, Duffy M, Hocking G. Central venous cannulation and monitoring in the ICU. Update in anaesthesia 2000;12(13):1-6.

[8] Chandrasekharan S, Chandrasekharan VP. Anatomical variations of the internal jugular vein in relation to common carotid artery in lesser supra clavicular fossa - a colour Doppler study. International journal of basic medical science 2011;1(5):235-41.

[9] Randalls B, Toomey PJ. Laryngeal oedema from a neck haematoma. A complication of internal jugular vein cannulation. Anaesthesia 1990;45(10):850-2.

[10] Brown CS, Wallace CT. Chronic haematoma-a complication of percutaneous catheterization of the internal jugular vein. Anaesthesiology 1976;45(3): 368-9. 